\title{
WITTGENSTEIN ON RULES AND PRACTICES
}

\author{
MARK MCCULLAGH \\ UNIVERSITY OF GUELPH
}

\begin{abstract}
Some readers of Wittgenstein think that his writings contain a regress argument showing that in explanations of linguistic correctness, the notion of participating in a practice is more basic than the notion of following a rule. But the regress argument bears equally on both of these notions; if there is an explanatory regress of rules, then there is an explanatory regress of practices as well. Why then does Wittgenstein invoke the notion of a practice, apparently by way of diagnosing the error on which the regress argument rests? I suggest that he invokes that notion to emphasize certain aspects of rule following which we are apt to neglect when we forget that rule following is-not rests uponparticipating in a practice. When we appreciate those aspects of rule/practice following we see the flaw in both regress arguments.
\end{abstract}

This was our paradox: no course of action could be determined by a rule, because every course of action can be made out to accord with the rule.... What this shows is that there is a way of grasping a rule which is not an interpretation, but which is exhibited in what we call "obeying the rule" and "going against it" in actual cases. (PI §201) ${ }^{1}$

\section{$\mathbf{S}$}

ome readers of Wittgenstein have thought that in the discussion that climaxes with this passage, Wittgenstein makes both a negative point and a positive one. The negative point is that we set up a paradox once we maintain that what makes a linguistic action correct ${ }^{2}$ is that it is an application of the rule for the use of the expression involved in it; and the positive point is that the way to avoid that paradox is to explain correctness by employing the notion of a practice instead of that of a rule. Robert Brandom, in Making It 
Explicit (1994), endorses Wittgenstein's arguments as making these points. I shall argue that to take the paradox of $\$ 201$ in that way is to underestimate the generality of the reasoning that leads to it. For there is a counterpart to that paradox that involves the notion of a practice. The paradox Wittgenstein presents gives us no reason to eschew one of these notions in favor of the other in explanations of linguistic correctness.

Why then does Wittgenstein invoke the notion of a practice at the start of $\S 202$, apparently by way of diagnosing the error upon which the paradox rests? What point could he be trying to make, if not that the paradox shows that we should work with the notion of a practice rather than that of a rule? I shall make the following suggestion. The point of those invocations is to emphasize that to follow a rule is to participate in a practice, and thereby to motivate a rejection of a certain seemingly innocuous claim that is essential in generating the paradox. That claim is that a rule can always be incorrectly applied whenever it can be correctly applied. It seems attractive to make that claim only when we are thinking of rules as lacking some of the features of practices. Wittgenstein's aim in the rule-following discussions is to argue us out of thinking of rules in that way. He does not invoke the notion of a practice as a way of gesturing at a constructive proposal about what rule following "consists in." He uses the notion only to highlight one aspect of linguistic rule following, neglect of which can lead us into the paradox of Investigations $\$ 201$.

1. Imagine that someone correctly gives " 392 " when asked "What is the sum of 367 and 25?" Let us suppose that the expressions in the question have rules for their use. To generate the paradox of Investigations $\$ 201$, we now hold that what makes the answer correct is that it is an application of those rules. ${ }^{3}$ But it seems that in that situation there could also have been an application of those rules that was incorrect—for example, the response "382." On the explanatory strategy being assumed, its being an application of those rules makes it correct. But it isn't correct. Hence a paradox. ${ }^{4}$ Let us register two of the assumptions at work in this line of thought:

1) What makes a speech act correct is that it is an application of the rule for the use of the expression involved in that act.

2) Any rule that can be correctly applied, in a given situation, can also be incorrectly applied in that situation.

At least one of these assumptions must be rejected, if we are to avoid the paradox. Some philosophers have thought that Wittgenstein wants us avoid the paradox by endorsing (2) and on that basis rejecting (1). They have thought that (2) reflects an important truth about rules. I shall argue that while we should reject (1), we should not take Wittgenstein to have shown that we should do so on the basis of (2), since Wittgenstein not only rejects (2) but gives reasons for doing so-reasons that become apparent once we see the real point of his invocation of the notion of a practice. 
2. Before discussing (2) on its own, I want to examine its relation to (1). Consider what is required to falsify (1). Since it's a universally quantified statement, all that is required to falsify it is one case in which what makes a linguistic action correct is not that it is an application of the rule for the use of the expression involved in it. An incorrect application will be such a case; obviously its being an application of the relevant rule doesn't make it correct, since it's incorrect.

We know that there are at least some incorrect applications of linguistic rules because we have all been party to, or at least witnessed, disputes over the use of this or that linguistic expression, and disputes are cases in which incompatible applications are made-applications at least one of which must be incorrect. The rule for the use of a predicative expression, for example, might be applied by one speaker so as to issue in an assertion of a predication of that expression of some singular term, while also possibly being applied by another speaker, so as to issue in a denial of a predication of that expression of that singular term. Since it cannot be correct both to assert and to deny the same such predication in the same situation, these cases are ones in which at least one of the applications of the rule is incorrect. ${ }^{5}$

Our experience of using our language, then, supplies counterexamples to (1). Now consider what (2) says. (2) says that in any situation in which a rule can be correctly applied, it can also be incorrectly applied. This is not just the claim that there are some situations in which some possible applications of a rule are incorrect. What (2) says is much stronger than that. (2) says that any situation in which a rule can be correctly applied is a situation in which it can be incorrectly applied. Since incorrect applications falsify (1), (2) entails that any situation in which a rule can be correctly applied is a situation in which there are possible applications that are counterexamples to (1).

So there are two possible reasons for rejecting (1). The first is the claim that some speech acts are made in situations in which the rule for the use of the expression involved in the speech act has applications in which at least one is incorrect. That claim is one we're entitled to make on the basis of our experience of using our language with others. Another reason to reject (1) is commitment to (2) - to the claim that all correct applications of rules are made in situations in which incorrect applications are possible. This much stronger claim is not one that our experience of using our language entitles us to make. This is because we have not been party to, or witnessed, disputes breaking out in all situations in which rules for the use of expressions in a language are applied. In sum, we are entitled to reject (1) on empirical grounds; and if we are entitled—as on empirical grounds we are not— to endorse (2), we are for that reason also entitled to reject (1). Whether we are entitled to endorse (2) is still an open question.

3. There is another way to bring out the bearing that (2) has on (1). Since Wittgenstein's discussions of rule following, it has been well known that on 
the basis of (2) we can construct a powerful reductio against (1), the "regress of rules" argument. ${ }^{6}$

Suppose we have a correct assertion $A$ made with sentence $S$. (1) tells us that what makes it a correct assertion is that it is an application of the rule, call it $R_{1}$, for the use of $S$ in making assertions. (2), however, says that in place of $A$ there could have been an incorrect application of $R_{1}$; and an incorrect application of $R_{1}$ is an incorrect assertion since $R_{1}$ is a rule for making assertions. So it must not just be the fact that $A$ is an application of $R_{1}$ that makes it a correct assertion; it must be that $A$ is a correct application of $R_{1}$ that makes it a correct assertion. But now what makes $A$ a correct application of $R_{1}$ ?

To apply a rule such as $R_{1}$ is to perform a speech act, and therefore to do something that falls under the range of principle (1). That principle then tells us that what makes $A$ a correct application of $R_{1}$ - correct qua token of that type-is that it is an application of the rule for the use of $S$ in applications of $R_{1}$. The only nonquestion-begging explanatory route is to hold that this rule must be a rule other than $R_{1}$; call it $R_{2}$. But then just as before, we will find that only its being a correct application of $R_{2}$ could be what makes $A$ correct as an application of $R_{1}$. And we are off on an infinite regress-to explain the correctness of an action as a token of a given speech-act-type requires adverting to a rule for the performance of actions of that type with that expression, but (given (2) only its being a correct application of that rule could do the required explaining, and explaining its correctness as an application of that rule requires (given (1)) adversion to another rule, a rule for the use of that expression in speech acts characterized as applications of the first rule. And so on. This regress argument supplies another reason why endorsement of (2) requires rejection of (1).

4. In the preceding two sections we have seen that (2) is incompatible with (1), and that this incompatibility can be brought out by the regress-of-rules argument. One way to avoid the paradox of Investigations $\$ 201$, then, is to endorse (2) and, on that basis, to reject (1). But as I noted above, we are already entitled to reject (1) on empirical grounds. So we don't need to endorse (2) in order to avoid the paradox. What reason is there, then, to endorse (2)?

One could say that (2) is supported by the fact that there have been many cases in which a rule has been applied correctly by one person, and incorrectly by another, in the same situation. This is most clear with rules for the use of words; people dispute over their correct usage. There are many situations in which both correct and incorrect applications of a given rule are possible. These are supporting examples to (2). But (2) says that all situations in which a rule can be correctly applied are situations in which it can be incorrectly applied. So the support that the examples give to (2) would have to be inductive. But any such induction would be unconvincing. For there are many rules whose applications seem to generate no disputes-simple rules for the use of mathematical expressions, for example (PI §240). Thus we lack supporting examples from an entire class of applications. 
Another possible reason to endorse (2) is to take it as a misformulated truism. One could take it that when Wittgenstein says, presenting the paradox that "every course of action can be made out to accord with the rule" (PI $\S 201)$, he is claiming that every course of action can be made out to accord with an expression of the rule-an inscription of it, say on a signpost (as in PI $\S 198)$, or an utterance of it. The thought would be that the paradox of $\$ 201$ is generated not by (2) as we have it, but by that incontestable claim about $e x$ pressions of rules. On this reading, Wittgenstein makes an elementary blunder in presenting the paradox of $\S 201$ as having to do with rules. He forgets the distinction between rules and expressions of rules-inscriptions, utterances and such.?

It is worth noting that to think of the paradox as turning on this premise would motivate a certain contrast between the notion of a rule and that of a practice- a contrast that can encourage the thought that the paradox shows the latter notion somehow superior to the former. For while it makes sense to speak of expressions of rules-inscriptions, noises and such-it doesn't seem to make sense to speak of expressions of practices. For example, there is nothing odd in asking where a rule is written down or when it was promulgated; but there is something very odd in asking where a practice is written down or when it was promulgated. That would be a reason to think that the paradox of $\$ 201$ could be generated with the notion of a rule but not, in a corresponding fashion, with the notion of a practice. (In the next section I argue that this isn't so. Its not being so is, then, (by modus tollens) an additional reason not to take (2) as a misformulated truism.)

The problem with such a reading is that there is ample evidence that Wittgenstein does distinguish between rules and expressions of rules. It's not just charity that rules out our attributing such a misformulation to Wittgenstein. On several occasions, it's his own careful employment of the distinction that he would stand accused of neglecting, on this reading of a crucial passage in the Investigations. ${ }^{8}$ Assumption (2) does not merely express the truism that different inscriptions or utterances have different significances in different languages, or anything like that. No such truism supports the paradox of $\$ 201$ because that paradox is presented by a philosopher who does distinguish between rules and expressions of rules, as having to do with rules.

5. A more interesting reason to endorse (2) is the thought that there's something about rules that makes (2) true of them, that it's in the nature of a rule to have possible applications that are incorrect in any situation in which there are possible applications that are correct. If that's why one thought (2) true, one would look for a notion that supported explanations of linguistic correctness and incorrectness, but concerning which there was no counterpart to (2).

The notion of a practice can be thought to fit that bill. In this spirit, Robert Brandom, in his book Making It Explicit (1994), argues that we can avoid the paradox of PI $\$ 201$ by working with the notion of a practice rather 
than that of a rule. ${ }^{9}$ In this section I examine Brandom's argument for that conclusion.

Brandom reads Kant and Frege as having worked with what he calls a "regulist" conception of norms, according to which "to assess correctness is always to make at least implicit reference to a rule or principle that determines what is correct by explicitly saying so" (20). He reads Wittgenstein, in turn, as having shown that we cannot conceive of all norms on the regulist model:

In the best-known portion of his discussion of rule-following in the Philosophical Investigations, Wittgenstein argues that proprieties of performance that are governed by explicit rules do not form an autonomous stratum of normative statuses, one that could exist though no other did. Rather, proprieties governed by explicit rules rest on proprieties governed by practice. Norms that are explicit in the form of rules presuppose norms implicit in practices. (20)

According to Brandom, this is shown by "Wittgenstein's regress argument." As we have seen, that regress argument establishes the inconsistency of principles (1) and (2); and in the context of an endorsement of (2), therefore, motivates a rejection of (1). The argument Brandom presents has this shape. As he presents it, the first step in the argument is the claim that "applying a rule in particular circumstances is itself essentially something that can be done correctly or incorrectly" (20)_this is our principle (2). Next we ask what determines applications as correct or incorrect, what makes them so. Obviously it couldn't be, à la (1), their merely being applications that makes the correct actions correct; it must be their being correct applications- "the rule determines proprieties of performance only when correctly applied" (20, my emphasis). But what makes them correct applications?

If the regulist understanding of all norms as rules is right, then applications of a rule should themselves be understood as correct insofar as they accord with some further rule. [This is the counterpart in Brandom's argument to our principle (1).] Only if this is so can the rule-conception play the explanatory role of being the model for understanding of all norms. (20)

And here, obviously, we have a vicious regress.

Brandom's argument does succeed in establishing the incompatibility of the following two claims: first, that "the rule-conception play[s] the explanatory role of being the model for understanding all norms"; and second, that "applying a rule ... is itself essentially something that can be done correctly or incorrectly" (20). The former is the counterpart in Brandom's terms to our principle (1), and the latter is almost an exact statement of our principle (2). Brandom wants to reject the former claim on the basis of the latter, and this accords with our earlier diagnosis $(\S 3)$ on which the regress argument establishes that (1) and (2) are incompatible. 
However, Brandom claims that the regress argument has in addition another conclusion. "The conclusion of the regress argument is that there is a need for a pragmatist conception of norms-a notion of primitive correctnesses of performance implicit in practice that precede and are presupposed by their explicit formulation in rules and principles" (21). I shall next argue that this additional conclusion does not follow from the regress argument. Far from it: there is a strict counterpart to the regress-of-rules argument, that can be used with equal effectiveness against Brandom's pragmatist conception of norms. Call it the "regress-of-practices" argument.

The regress-of-practices argument goes as follows. Instead of asking how an action's being an application of a rule could make it correct, we ask, instead, how an action's being a participation in a practice could make it correct. Just as it seems that a rule can be applied in a given situation either correctly or incorrectly (this is principle (2)), so too, it seems, a practice can be participated in, in a given situation, either correctly or incorrectly. (Think of a practice of crossing oneself as one enters church. One could participate in it incorrectly by crossing oneself in an incorrect manner when entering church.) Just as before, we can insist that an action's correctness could be explained by its participating in a practice only if it participates correctly in that practice. And how are we to explain the correctness of the participation? To say that all correctness is to be explained as participation in a practice-this would be a pragmatist counterpart to (1) - commits us to saying that there's another practice, one of assessing (as correct or incorrect) participations in the first, and that the correctness of a participation in the first practice is to be explained by the correctness of an action that participates in the second, assessing, practice. (To continue our example, think of a practice of responding to others' crossings of themselves as done correctly or incorrectly.) But then how to explain the correctness of the participation in the assessing practice? We get another vicious regress, but of practices rather than rules.

The parallels between the two arguments are easy to see once the possibility of a counterpart to the argument that Brandom presents is raised. Here, for instance, is Brandom's summary of the regress-of-rules argument:

Norms explicit as rules presuppose norms implicit in practices because a rule specifying how something is correctly done . . must be applied to particular circumstances, and applying a rule in particular circumstances is itself essentially something that can be done correctly or incorrectly. (Brandom 1994, 20)

Here is that summary transposed into the regress-of-practices argument:

Norms implicit as practices presuppose [yet another sort of norm, by parity of reasoning] because a practice determining how something is correctly done ... must be participated in particular circumstances, and participating in a practice in particular circumstances is itself essentially something that can be done correctly or incorrectly. 
Replacing the notion of a rule with that of a practice does not avoid a regress, because the mere introduction of the latter notion does nothing to cast doubt on the truth of the counterpart to (2) - namely, the claim that any situation in which a practice can be participated in correctly is a situation in which that practice can also be participated in incorrectly. As long as counterparts to (1) and (2) are in place, a regress argument can be run. And Brandom does not undertake to show that no such counterparts are in place when it comes to the notion of a practice. The appeal to practices, as a grounder of semantic explanations, is no better off than the appeal to rules. ${ }^{10}$

Not on the basis of a comparison of the notion of a rule with that of a practice, then, should we take ourselves to be entitled to (2). For a counterpart to (2) that is about practices seems just as plausible as does (2) itself.

6. Why would anyone have thought that when we use the notion of practice we are less liable to the paradox of $\$ 201$ than we are when we use the notion of a rule?

One reason, of course, is the thought that Wittgenstein himself makes such a claim when he famously tells us that "To obey a rule, to make a report, to give an order, to play a game of chess, are customs (uses, institutions)" (§199), or when, after presenting the paradox of PI $\$ 201$, he says, "And hence also 'obeying a rule' is a practice" $(\$ 202)$. The problem with this thought, though, is that when we read them straightforwardly these passages simply don't say that one notion is explanatorily presupposed by the other. If that's what Wittgenstein meant to be saying, he would have expressed himself by saying that obeying a rule presupposes, somehow rests upon, a practice. But he says that obeying a rule is a practice. The idea he is expressing in these remarks is not that the notion of a practice is more explanatorily basic than the notion of a rule-that "norms explicit as rules presuppose norms implicit in practices." The idea is, rather, that since rules are practices, we should not think of rules as if they lack any of the features of practices.

Another possible reason for thinking that the notion of a practice is less paradox-generating than the notion of a rule is supplied by a certain conception of how rules get their normative grip on actions. We think of rules, and not of practices, as necessarily having propositional contents. In Brandom's metaphorical terms, we think of rules as "saying" this or that. But we also think of rules as having propositional contents that are general, that is, contents that do not specify particular actions as correct or incorrect. And it is possible to think of rules in a way that makes this out to be a flaw in them.

Recall that on Brandom's presentation, the regress of rules gets started because no rule "says" of any particular action whether it is correct or incorrect; the rule's necessarily general content must be applied to the particular action. Now, how might an application of a rule, conceived of in this way, go astray? The rule has a general propositional content, specifying how speech acts of a certain type are to be performed with tokens of a certain linguistic 
expression-type. So an application could err by misidentifying a given token as being of that expression-type, or by misidentifying a speech act as being of that speech-act-type, or by misidentifying the circumstances as being of the sort the rule says must obtain for the use (of that expression in speech acts of that type) to be correct. For example, if the rule is "Only assertively apply the word 'dawn' to the sun's rising," then to apply its general content to a particular case could involve a misidentification of some string as being the word "dawn," or of some action as being an assertion, or of some circumstance as being that of the sun's rising. So there are at least three ways in which the move from the rule's general content to the specification of the action in terms of particulars can go astray. This would be a reason to endorse (2).

Premise (2) of the paradox is supported, therefore, by a view according to which rules for the uses of words fail to settle, on their own, whether particular actions are correct, because they fail to do so in the only way that rules could, that is, by having propositional contents that specify those particular actions in terms of their particulars. That the propositional contents of linguistic rules are general, therefore, can seem to be a reason to endorse (2).

Notice that there is no corresponding reason to endorse a counterpart of (2) that concerns practices. For we don't even think of practices as having propositional contents in the first place, let alone ones that are general and which therefore can be thought to stand in need of being made more particular. For this reason, therefore, it could be thought that the notion of a practice does not generate any paradox corresponding to that of Investigations $\$ 201$, which involves rules.

But we know that there must be something wrong with this thought since we saw in $\S 5$ that the regress of rules has a counterpart regress of practices. And indeed there is something wrong with it. For this conception of how rules get their normative grip on actions has no support in our ordinary notion of a rule. When we find ourselves thinking of an action $A$ as one that is correct according to a given rule, we never find ourselves thinking of that rule as having, as its propositional content, that $A$ is correct. If reflection on the ordinary notion of a rule did tell us that a rule settles it that an action is correct or incorrect only by specifying it in terms of its particulars, then we would find ourselves attributing to rules propositional contents that specify particular actions as correct whenever we found ourselves describing particular actions as correct according to those rules. But we don't. There just doesn't seem to be anything to the mere notion of a rule, that motivates thinking of their contents as standing in need of being made more particular in order to get their normative grip on actions.

Should we then insist that in virtue of having the general content that it has, a rule does succeed in "saying" of particular actions whether they are correct or incorrect? Perhaps, if by the metaphor of a rule's "saying" something we mean nothing more than that it has it as as logical consequence (via universal instantiation) of its propositional content. But the point I wish to emphasize 
is that while that metaphor can be employed in a way that motivates both an endorsement of (2) and a rejection of (2)'s counterpart concerning practices, it shouldn't. For there is no support in our ordinary use of the concept of a rule, for thinking that the general content of a rule stands in need of being made more particular in order to succeed in "saying" of this or that particular action that it is correct or incorrect.

Premise (2) is, like (1), a universal generalization. All that is required for its falsity is that there be one situation in which a rule for the use of an expression can be correctly applied but not incorrectly applied. But we have no reason to think that such counterexamples would be ones in which the rules have propositional contents that specify or state, in terms of particulars, which actions accord with them and which conflict. To think that any counterexamples to (2) would have to be like that would be to work with a doubly flawed conception of how rules get their normative grip on actions. For that conception is unsupported by reflection on our ordinary concept of a rule, and it encourages the false thought that the regress of rules has no counterpart regress concerning practices.

7. The reasons for endorsement of (2) that we have looked at are unconvincing. (2) isn't supported by the existence of many cases in which a rule has both correct and incorrect applications, for (2) says, much more strongly, that all cases are like that ( $\$ 4)$. Nor may we argue in support of (2) by saying that it isolates the paradox-generating flaw in the notion of a rule that is not shared by the notion of a practice, for there is no such flaw (\$5). Nor, finally, is (2) supported by the observation that the rules we're interested in don't have contents that specify actions in terms of their particulars, since there is no reason to insist that only by having such a content could a rule settle it that an action is correct or incorrect ( $\$ 6)$.

On the other hand I think that Wittgenstein shows us good reasons to reject (2), that is, to reject the claim that any situation in which a rule can be correctly applied is a situation in which it can be incorrectly applied. Wittgenstein himself rejects (2)-this much is clear in the Investigations, as I shall show-but his reasons for rejecting it are more evident in some claims he makes in his discussion of rule following in Remarks on the Foundations of Mathematics. When we understand those reasons, I think we shall find a rejection of (2) intuitively appealing.

In the Philosophical Investigations, (2) is put into the mouth of one of that book's imaginary interlocutors. It is an interlocutor to whom Wittgenstein responds in the tone of a correcting schoolmaster:

"But how can a rule show me what I have to do at this point? Whatever I do is, on some interpretation, in accord with the rule."-That is not what we ought to say, but rather: any interpretation still hangs in the air along with what it interprets, and cannot give it any support. Interpretations by themselves do not determine meaning. (\$198) 
We may be frustrated at Wittgenstein's not offering a more positive-sounding remark as a corrective, but it is clear at least that he rejects the interlocutor's assertion of something very close to (2). That any rule may be applied so as to license any action is "not what we ought to say."

I said that one reason we could have for rejecting (1) is consideration of particular cases of rules that have conflicting applications. The only argument in support of (2) that we could base on that sort of evidence was uncompelling (§4). Now consider some particular cases that Wittgenstein discusses in Remarks on the Foundations of Mathematics, and about which he makes claims incompatible with (2):

[T] he truth of the proposition that $4+1$ makes 5 is, so to speak, overdetermined. Overdetermined by this, that the result of the operation is defined to be the criterion that this operation has been carried out. (1978, vi.16)

450 succeeds 449 . That is not the empirical proposition that we come from 449 to 450 when it strikes us that we have applied the operation +1 to 449 . Rather it is a stipulation that only when the result is 450 have we applied this operation. (1978, vi.22)

The idea he expresses in these passages is that there are some situations in which the only applications to be made of the rule for the use of a certain expression are correct ones, because to use that expression otherwise than as that rule recommends is not, in that situation, to apply that rule at all. This claim is incompatible with principle (2).

Note the quantifiers here. Wittgenstein is not suggesting that there are some rules that can never be misapplied. Nor is he saying that there are some situations in which no rules can be misapplied. The claim suggested in the two passages I have quoted is that there are some pairs - of a rule for the use of a certain sign in certain types of speech acts, and a situation-such that in that situation, that rule cannot be misapplied.

Another way to misunderstand the claim Wittgenstein is making is by taking it as the claim that there are cases in which the speaker cannot apply the rule incorrectly in a given situation because in that situation, there's something forcing the speaker to apply that rule correctly. That would be an absurd thing to say.

The point Wittgenstein is making, in these passages, rests on the fact that the rules we are discussing are rules for the use of expressions, and this means their use in speech acts. The rule for the use of "dawn," for example, is not violated when someone is merely singing a tune in which that word occurs, in a situation in which that word is not correctly predicated of anything salient. The rule is only applied when the word is being used (not merely quoted, say) in the performance of a speech act of some type. With this point in mind we can put Wittgenstein's claim as follows. He is saying that a would-be use of a word or sentence can be self-disqualifying in the following sense: it can manifest a 
misunderstanding of the word or sentence that is serious enough to disqualify that particular tokening of it from being a speech act (or, as in the examples he uses, the performance of an arithmetical operation).

Wittgenstein's point here is very close to a claim that Grice and Strawson (1956) made in their response to Quine's “Two Dogmas of Empiricism” (1951). Wanting to vindicate something worth calling an analytic/synthetic distinction, Grice and Strawson pointed to a difference between two general sorts of reactions speakers can have to each others' vocalizations or inscriptions. On the one hand, speakers can treat such an event as a successful speech act, as an event that has a propositional content which constrains what counts as a good reason for performing an action with that content. On the other hand, speakers can treat such an event as not being a successful speech act, by not acknowledging anything as being a content-constrained reason for performing that action. ${ }^{11}$ To say "My neighbor's three-year-old child is an adult" is not, Grice and Strawson say, to make an assertion with a propositional content; as thus uttered, those words "have no sense" (151). To hook up Grice's and Strawson's claims about their example with the claim that Wittgenstein makes about his, all that is needed is the idea that to token an expression constructed of words in a public language in such a way that they "have no sense" is not to apply the rule for the use of those words in that language. ${ }^{12}$

8. How plausible is this claim that there are counterexamples to (2)? Consider what rejecting it requires. Rejecting it requires holding that the speaker who uses the sign " 1 " to take him from " 449 " to " 454 ," for example, is not performing a self-disqualifying (would-be speech) act. It requires holding that such a speaker can thereby assert that the sum of 449 and one is 454, or can thereby add 449 and one.

The natural worry to have about such a proposal is that it conflicts with a widely acknowledged—indeed, near-truistic-linkage between the ideas of understanding and of performing a speech act. The linkage is that there is a sort of understanding that is a necessary condition on performing a speech act; as Colin McGinn has put it, there is a "direct conceptual connection between the concept of understanding and the concepts of action, in particular linguistic action" $(1984,122)$. It is easy to see why. For there is an incoherence even in the idea of someone performing an action while having nothing worth calling an understanding of what he is doing; and still greater incoherence in the idea of someone performing a speech act—asserting that $p$, asking whether $p$-while having nothing worth calling an understanding of the propositional significance it has.

It would be good not to have to couple a rejection of Wittgenstein's putative counterexamples to (2) with a rejection of the idea that there is such a linkage between the idea of understanding a word and the idea of performing a speech act with it. But to call these examples speech acts is to invite the charge that one is rejecting that linkage. For the proponent of the linkage is 
certainly going to hold that someone who uses the sign " +1 " to take him from " 449 " to " 454 " fails to possess anything worth calling an understanding of the sign "+1." For if he does not insist on that, it is hard to see what he would insist on, as a necessary condition on the linkage's obtaining in this case.

Looking elsewhere, then, there is at least one other objection to Wittgenstein's claim that does not appear to involve rejecting the idea that having something worth calling an understanding of one's words is a necessary condition on being able to perform speech acts with them. It could be put as follows.

Surely someone can apply the rule for the use in English of the sign " +1 " so as to assert that the sum of 449 and one is 454 , or so as to add 449 and one to get 454 . For he could have understood the explanation he'd been given of that sign, and thereby been endowed with the ability to make assertions and perform additions with it, while having misunderstood the explanation he'd been given of some other sign in terms of which that explanation was given. Suppose, for instance, that he had been told that " +1 " means the same as "plus one," but had misunderstood the explanation he'd been given of the sign "plus one."

The problem with this line of thought, though, is that we're not entitled to say that the speaker did understand the explanation of the expression " +1 " that was given to him (see McGinn 1984, 117-9). This is because for an explanation to endow someone with understanding, it must itself be understood. To supply someone only with a way of trading off one expression for another is to enable them only to perform what Wittgenstein calls an "interpretations," that is, "replacement[s] of one expression of the rule [for the use of a linguistic expression] for another" (PI §201). The claim we should make in reply to the objection, then, is precisely the one that Wittgenstein makes to his interlocutor of $\$ 198$ - that interpretations by themselves do not determine meaning. To explain to a speaker that one linguistic expression means the same as another does not on its own endow that speaker with the ability to perform speech acts with it, that is, to perform actions that are correct or incorrect according to the rule for the use of that expression. It is a crucial point about the notion of interpretation, as Wittgenstein defines it, that the ability to give interpretations of a rule does not require the ability to apply that rule.

It is far from clear, then, that reason demands endorsement of (2); when we think of certain examples of speakers tokening certain expressions in certain situations, a rejection of (2) becomes entirely plausible, and, indeed, philosophically respectable. This is because a defense of those counterexamples can adduce in its support the distinction, basic in the philosophy of language, between merely tokening an expression and using it to perform a speech act.

I shall not here attempt a fuller defense of the claim that Wittgenstein's examples are counterexamples to (2). My purpose in this and the preceding section has been merely to show that Wittgenstein does reject (2) and that he adduces examples that support such a rejection. 
9. I have suggested that Wittgenstein's reason for rejecting (2) is that he holds that there are some situations in which any would-be uses of certain linguistic expressions are self-disqualifying from being uses (in speech acts). At the beginning of this paper I suggested that we can see his invoking the notion of a practice, after his presentation of the paradox of $\S 201$, as a way of pointing to the existence of such cases. What reason is there for taking that invocation in that way rather than in what is probably the usual way-as a gesture towards a constructive story about what linguistic rule following "consists in"-or more broadly, as a gesture towards an account of the "nature of the normative"?

First, of course, there is the reason that the arguments leading up to PI $\S 201$ give us no reason to think that a story told using the notion of a practice is any less vulnerable to the paradox of that section than a story told using the notion of a rule. Of course, it is possible that Wittgenstein himself did not realize this. Perhaps even he did not appreciate the generality of the reasoning that leads to the paradox of $\$ 201$, and thought that the way to resolve it is to tell a story with the notion of a practice that cannot be told with the notion of a rule. But we needn't be pushed into that corner. I think that we can account for Wittgenstein's invocations of the notion of a practice while crediting him with having appreciated the generality of the reasoning that leads to the paradox of $\S 201$.

That exegetical story starts with the observation that the distinction in terms of which we just articulated an intuitively plausible rejection of (2) - namely the distinction between merely tokening or quoting an expression in a language, and using it to perform a speech act-is precisely one that the notion of a practice puts us in mind of, and which we are not put in mind of by the notion of a rule. This motivates the suggestion that Wittgenstein used the notion of a practice simply to put us in mind of some facts about the use of language that we are not put in mind of by the notion of a rule, and not as a gesture at a constructive story that makes no explanatory use of the notion of a rule.

The notions of a rule and of a practice bring different implications in their respective trains when employed to describe the use of language. As was noted above, we think of rules as necessarily having propositional contents. To employ the notion of a rule, in describing the use of language, is to convey the important fact that there is correctness and incorrectness in such use. For the idea of propositional content brings with it the notions of truth and of justification, and either of these can support a conception of what correctness in the use of language is. But the idea that rules have propositional contents does not, on its own, convey two equally important facts: first, that there is more to performing actions of certain linguistic types than merely tokening sentences; and second, that it isn't a necessary condition on one's actions being governed by a rule, that one manipulate concrete expressions of that rule. Yet 
these points are conveyed by employment of the notion of a practice. Consider the first point. Although we do not think of practices as having propositional contents, we do think of them as necessarily specifying types of actions. Grammar alone seems to indicate this, for we speak not of it being a practice that $p$, but of it being a practice to $x$, where " $x$ " is replaced by a description of a type of action (perhaps supplemented by a description of the situations in which an action of such a type should be performed). This points us in the direction of thinking about which types of actions a practice specifies. The second point, it was noted earlier (§4), is one that the notion of a practice also brings with it - for the oddness in asking when a practice was promulgated, or where it is written down, plausibly reflects its not being a necessary condition on the existence of a practice that there be manipulations of concrete "expressions of" that practice. These implications are not incompatible. Each of them is, after all, reflected in our ordinary talk about each other as users of language, for we describe each other as speaking truly or falsely, with justification or without, with this or that sentence, and as making a speech act of this or that type. But neither the notion of a rule nor the notion of a practice suggests all of these important facts about what it is to use a language.

In the light of this, my suggestion is that Wittgenstein took his situation, in writing these parts of the Investigations, to be something along the following lines. He saw the notion of a rule and the notion of a practice as each serving to highlight different aspects of the meaningful use of language. He believed that either notion, leaned on exclusively, is apt to lead us astray in our thinking. (Something of this sort had come up earlier in the Investigations when Wittgenstein argued that "The forms that we use in expressing ourselves about propositions and thought stand in [the] way" of our understanding what propositions are and what thoughts are (PI §93).) However, when we get into trouble by employing one of them we can get out of it by bringing the other to bear. The idea is not that either of these notions implies something false, or anything incompatible with what the other implies, but that each of them has trouble-making potential because it fails to imply, or put us in mind of, an important truth about the use of language - a truth that the other notion does put us in mind of. Thus the notions of a rule and of a practice stand, in the rhetoric of the Investigations, in a mutually supplementing relation. When Wittgenstein invokes one, we should not take it that he is thereby rejecting anything implied by his employment elsewhere of the other. Rather, he is using one notion to put us in mind of something about the use of language that we would not be put in mind of, had he used the other notion in its place.

There should be no mystery about how a philosophical writer could find himself in such a situation. Wittgenstein was working with received conceptsthat of a rule and that of a practice or custom-and trying to forge out of them a description of language use that was less liable to lead us, via abstract reasoning in which ordinary users of those concepts seldom indulge, into 
what he thought was fruitless puzzling than some other descriptions framed using those same concepts.

If this exegetical suggestion is right, then we shouldn't view Wittgenstein's invocations of the notion of a practice as gestures (very frustrating ones they would be!) at a constructive theory—let alone one worth calling "pragmatist." I do not mean to deny that to many readers of the Investigations, the rule following considerations have "obvious constitutive and transcendental pretensions," as Paul Boghossian puts it $(1989,544$ n. 66). On the reading I'm suggesting, there are no such pretensions, and that goes against the feeling many readers have. But I think that that is a virtue of the reading rather than a flaw. For as Boghossian himself notes, it is difficult to take Wittgenstein's invocations of the notion of a practice as gestures towards a constructive theory while acknowledging that his oft-expressed view about philosophy is that it tells us nothing we don't already know-it merely describes and doesn't explain (e.g., PI $\S 122-9,435-6$ ). The fact that many readers of the Investigations have taken it to have "constitutive and transcendental pretensions" perhaps says more about their expectations when reading the Investigations than it does about its actual content.

10. For Wittgenstein, to interpret someone as applying linguistic rulesor, equally, as participating in linguistic practices-is already to undertake commitments sufficient to avoid the paradox of §201. To show that, and not to make a gesture at a constructive story about what rule following "consists in," or of the "nature of the normative," is the purpose served by his invocation at $\$ 202$ and elsewhere of the notion of a practice. Wittgenstein's idea is that we avoid the paradox of $\$ 201$ not by understanding our entitlement to describe someone as applying a rule, but by understanding what is involved in our describing someone in that way. Seeing his take on the rule-following considerations in this way is consistent with acknowledging that he invokes the notion of a practice apparently to point toward a way out of the paradox. We can read those invocations not as gestures towards a constructive account of "the nature of the normative," but simply as reminders of some important facts about the use of language that the notion of a rule fails to put us in mind of (but with which that notion is not incompatible). This reading has two virtues. The first is that it is consistent with crediting Wittgenstein with full recognition of the generality of the reasoning that leads to the paradox of PI $\$ 201$. The second is that it sets up no conflict between Wittgenstein's invocation of the notion of a practice and his overarching antireductive, antitheoretical commitments. 


\section{ENDNOTES}

For helpful discussions of predecessors of this paper I would like to thank Robert Brandom, Douglas Lavin, John McDowell, Ram Neta, and Douglas Patterson.

${ }^{1}$ I cite Philosophical Investigations as "PI" and Remarks on the Foundations of Mathematics as "RFM."

${ }^{2}$ I mean correct qua linguistic action. This can be thought of in different ways, most commonly either as a matter of truth or as a matter of entitlement. But for the arguments I'll be considering it doesn't matter which particular conception one has of the sort of correctness distinctive of linguistic actions.

${ }^{3}$ I'm working with a very minimal notion of "applying a rule," on which to say that someone applies a rule is not to say they have any explicit conception of that rule in mind, or even that they have an intention to follow it. On the usage I'm working with (and with which Wittgenstein shows we can generate a paradox), to apply a rule is simply to perform an action that either is correct according to that rule, or is incorrect according to that rule. In another terminology, it is to perform an action that is governed by that rule.

${ }^{4}$ Calling it a paradox reflects commitment to the prima facie plausibility of the assumptions on which it rests. By now the term "paradox," for the result Wittgenstein wants to show us how to avoid, is so well entrenched that I will use that term without defending the idea that all the assumptions on which that result rests are prima facie plausible.

${ }^{5}$ Of course, the traditional (pre-Quinean) way to characterize many of these cases of disagreement is as disagreement over the meanings of words rather than as disagreement over matters of word-independent fact. We needn't endorse that distinction here, since what makes for the falsity of (1) is simply the fact of disagreement - the fact that there are possible applications of a given rule in a given situation such that at least one of them is incorrect.

${ }^{6}$ The argument is suggested especially by PI $\S 84$ and 201.

${ }^{7}$ Gordon Baker makes a proposal along these lines, claiming that "Wittgenstein recommended viewing rules as symbols or instruments with particular uses or ranges of use" $(1981,59)$. Baker acknowledges that this recommendation is one to which "any competent philosopher" would object (61). But I do not think that Wittgenstein makes it, or is committed to making it (see next note).

${ }^{8}$ See $\$ 198$ where both notions are in play and distinguished. Or consider the sections where the notion of a rule receives its first treatment. After introducing the grid-describing language of $\$ 48$, Wittgenstein considers the question of what the correspondences between the letters of the language and the colored squares might "consist in" (\$51). He says that there are various things they could consist in; "what we call a rule of a languagegame may have very different roles in the game" (\$53). According to Wittgenstein, one thing it could consist in is in the fact that those playing the language game play it in such a way that "an observer can read these rules off from the practice of the game-like a natural law governing the play" (\$54). There is no indication here that Wittgenstein takes rule following to require the manipulation of concrete "expression of" (\$53) the rule, let alone that he is so confused as to speak of concrete expressions of a rule as being the rule.

${ }^{9}$ Others have made similar claims, but here I examine Brandom's presentation because he attempts in some detail to lay out exactly how the rule-following considerations support the pragmatist conclusion. 
${ }^{10}$ To say this is consistent with holding (as I do) that it is a great aid to understanding certain rules/practices, to see how they serve to make others explicit. The substance of Brandom's book is devoted to showing in detail how this is the case with rules/practices involving certain semantic and logical vocabulary, the understanding of which has always caused philosophers consternation.

${ }^{11}$ Content-constrained" is needed here, because we could without contradiction acknowledge that someone's singing of a lyric, say, has got a propositional content while also maintaining that whatever reasons they have for singing it have nothing to do with its having the propositional content that it has. (If there were content-constrained reasons-for, then we'd be treating the singing as something more like an assertion than a mere tokening, and to do that is to respond to it in the first-described kind of way.)

${ }^{12}$ I believe that Wittgenstein also gives good reasons for thinking that there are counterexamples to (2) that involve the use of linguistic expressions to make empirical claims. (See especially On Certainty's discussion of the "peculiar logical role" of certain empirical propositions, $\S \S 136 \mathrm{ff}$, especially $\S \S 155-6$ : "In certain circumstances a man cannot make a mistake.") But my present purposes do not require getting into that issue. It is (2)'s falsity that matters at present, not how extensive is the range of counterexamples to it.

\section{BIBLIOGRAPHY}

Baker, Gordon. 1981. "Following Wittgenstein: Some Signposts for Philosophical Investigations §§143-242.” In Wittgenstein: To Follow a Rule, ed. Steven H. Holtzman and Christopher M. Leich, 31-71. London: Routledge \& Kegan Paul.

Boghossian, Paul. 1989. "The Rule-Following Considerations.” Mind 98: 507-49.

Brandom, Robert. 1994. Making It Explicit. Cambridge, MA: Harvard University Press. Grice, Paul, and P. F. Strawson. 1956. "In Defense of a Dogma." Philosophical Review 65: 141-58.

McGinn, Colin. 1984. Wittgenstein on Meaning. Oxford: Basil Blackwell.

Wittgenstein, Ludwig. 1953. Philosophical Investigations. Translated by G. E. M. Anscombe. Oxford: Blackwell.

. 1969. On Certainty. Translated by G. E. M. Anscombe and G. H. von Wright. Oxford: Blackwell.

. 1978. Remarks on the Foundations of Mathematics. 3d ed. Edited by G. H. von Wright, Rush Rhees, and G. E. M. Anscombe. Translated by G. E. M. Anscombe. Oxford: Blackwell. 